\title{
GT HistóRIA dA EduCAÇÃo dA ANPED \\ - PANORAMA TEÓRICO-METODOLÓGICO NOS ENCONTROS NACIONAIS DE 2015 E 2017
}

\author{
GT History of ANPED Education - Theoretical-Methodological \\ Overview at National Meetings Of 2015 and 2017
}

GT Historia De La Educación De La ANPED - Panorama
Teórico-Metodológico en los Encuentros Nacionales de 2015 y 2017

ResUmo O GT 02 - História da Educação, da ANPED - Associação Nacional de Pós-Graduação e Pesquisa em Educação é o objeto de estudo desta pesquisa, que visa identificar os principais temas, correntes historiográficas e teóricas neste grupo de trabalho, nos encontros nacionais de 2015 e 2017. Parte-se do panorama do desenvolvimento do GT 02, seguido da análise de todos os trabalhos apresentados nos anos indicados, principalmente a partir dos títulos, temáticas, tipos de pesquisa, campos temáticos investigativos e referenciais teóricos. A principal fonte de pesquisa foi o site da ANPED e as análises contam com o embasamento de pesquisa bibliográfica e referencial teórico específico dos principais aspectos levantados no estudo dos referidos trabalhos. A pertinência está em obter um conjunto de dados que permitam desvelar como esses pesquisadores em específico, como um grupo, estão lidando com as complexidades que envolvem a pesquisa em História da Educação, nos meandros de uma proposta de pesquisa que permeia tanto o campo da História, quanto da Educação, e por isso abarca uma miríade de questões e temas.

Palavras-chave: ANPED. GT 02 - História dA EducAÇÃo. HISTÓRIA. EDUCAÇÃO.

ABSTRACT The GT 02 - History of Education, from ANPED - National Association of Postgraduate and Research in Education is the object of this study, which aims to identify the main themes, historiographic and theoretical currents in this work group, at the national meetings of 2015 and 2017. It starts from the development of GT 02, followed by the analysis of all the papers presented in the years mentioned before, mainly from the titles, themes, types of research, thematic research fields and theoretical references. The main source of this research was the ANPED website and the analyzes rely on a bibliographical research base and specific theoretical reference of the main aspects raised in the study of the mentioned works. The pertinence is to obtain a set of data

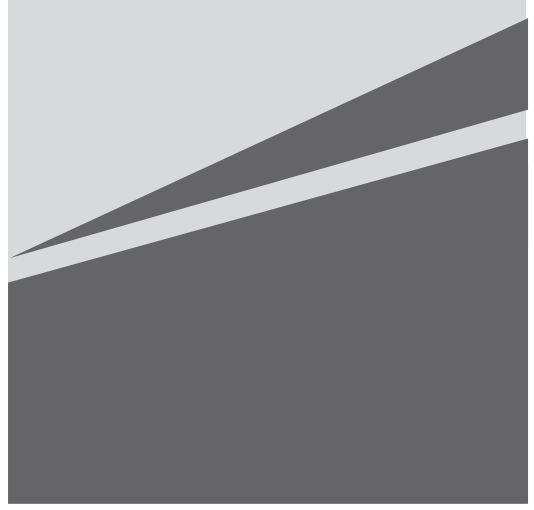


that will reveal how these specific researchers, as a group, are dealing with the complexities involved in research in History of Education, in the meanderings of a research proposal that permeates both the field of History and Education, and therefore encompasses a myriad of issues and themes.

KEY-WORDS: ANPED. GT 02 - HISTORY OF EDUCATION. HISTORY. EDUCATION.

RESUMEN El GT 02 - Historia de la Educación, de la ANPED - Asociación Nacional de Postgrado e Investigación en Educación es el objeto de estudio de esa investigación, que busca identificar los principales temas, corrientes historiográficas y teóricas en ese grupo de trabajo, en los encuentros nacionales de 2015 y 2017. Se parte del panorama del desarrollo del GT 02, seguido del análisis de todos los trabajos presentados en los años indicados, principalmente a partir de los títulos, temáticas, tipos de investigación, campos temáticos investigativos y referenciales teóricos. La principal fuente de investigación fue el sitio de la ANPED y los análisis cuentan con base de investigación bibliográfica y referencial teórico específico de los principales aspectos planteados en el estudio de los referidos trabajos. La pertinencia está en obtener un conjunto de datos que permitan desvelar como esos investigadores en específico, como un grupo, están lidiando con las complejidades que involucran la investigación en Historia de la Educación, en los meandros de una propuesta de investigación que permea tanto el campo de la Historia, como de la Educación, y por eso abarca una miríada de cuestiones y temas.

PALABRAS CLAVE: ANPED; GT 02 - HISTORIA DE LA EdUCACIÓN; HISTORIA; EDUCACIÓN.

\section{INTRODUÇ̃̃o}

dentificar os temas, teóricos e principais correntes historiográficas que vêm sendo discutidos por uma parcela dos pesquisadores no campo da História da Educação no Brasil é o objetivo desta pesquisa, ao analisar trabalhos apresentados no GT 02 - História da Educação, nos anos de 2015 e 2017, equivalentes aos encontros nacionais $37^{\circ}$. e $38^{\circ}$. da ANPED - Associação Nacional de Pós-Graduação e Pesquisa em Educação.

Considera-se que a História da Educação é extremamente abrangente, devido à sua interlocução com diferentes outros campos das ciências e pela multiplicidade de possibilidades de elementos a serem pesquisados. É uma proposta de pesquisa tanto dentro da
História, quanto da Educação, que ainda está conquistando espaço e respeito e, portanto, entende-se que há a necessidade de discussões em relação aos seus aspectos gerais e específicos, assim como, suas dinâmicas teórico-metodológicas.

Em sua obra "Aberturas para a História da Educação”, Saviani (2013) salienta a relevância do estudo da história ao afirmar que a "historicidade do fenômeno educativo [...] coincide com a origem do próprio homem" (p. 7), ou seja, na História da Educação os significados de história e educação estão intimamente imbricados, tanto na escolha do objeto, quanto no enfoque de uma pesquisa.

De acordo com Fonseca (2003), a História da Educação surge no Brasil como uma disciplina nos cursos de formação de professores e, no século XXI, ainda está presente 
nos cursos de Pedagogia. Nessa disciplina, há a preocupação de "[...] pensar no justo equilíbrio entre inovação e tradição" (FARIA FILHO; RODRIGUES, 2003, p. 173). Ainda sobre o tema, Borges e Gatti (2010) defendem que é preciso estreitar os laços entre a disciplina na graduação e na pós-graduação.

No tocante à História da Educação, como um campo de pesquisa da pós-graduação, houve, no último século, uma ampliação de novas formas de pensar, pesquisar, fazer e narrar a História para o campo da Educação, que trouxe mudança no modo de problematizar a pesquisa desse campo. Nunes (1996), ao introduzir um estudo sobre pesquisas na História da Educação, por meio de análise dos manuais de História da Educação, evidencia essas múltiplas possibilidades de fontes na pesquisa histórico-educacional. Ainda de acordo com a autora, esse alargamento de fontes no estudo da História da Educação tem gerado uma preocupação cada vez maior por parte dos historiadores da educação em relação à aquisição de formação adequada para se efetuar pesquisas. Esse campo tem trabalhado com novos desafios para além da "documentação manuscrita e impressa, atas, normas, regulamentos e manuais de ensino, como por exemplo, história e memória de sujeitos, iconografia, museus escolares, imprensa periódica" (p. 67).

Assim, é dentro dessa perspectiva de História da Educação que se procura aqui compreender quais os principais temas e correntes históricas que têm sido trabalhados dentro de um grupo de trabalho específico da ANPED, no afã de contribuir para a construção de um panorama geral desse campo científico.

\section{Panorama do desenvolvimento do GT 02 - História da EduCAÇÃo da ANPED}

A ANPED - Associação Nacional de Pós-Graduação e Pesquisa em Educação - é uma entidade sem fins lucrativos fundada em 16 de março de 1978 com a finalidade de con- globar programas de pós-graduação stricto sensu em educação, no intuito de desenvolver o ensino e pesquisa, assim como, promover encontros para discussão e disseminação do conhecimento.

Os Grupos de Trabalho (GTs) da ANPED são instâncias de agregação e socialização de conhecimento e pesquisas. Cada GT tem sua própria história e dinâmica, o GT 02 - História da Educação - surge em 1984, na $7^{a}$. Reunião Anual, realizada em Brasília, como fruto da proposta de Luís Antônio Cunha. No site da ANPED há informações sobre o histórico do GT 02, onde é explicitado que esse grupo de trabalho surgiu para discutir os resultados de pesquisas do campo, ao abordar problemas relevantes, metodologias e intercâmbio de bibliografias. Destaca-se que a respeito dos desafios do GT desde a sua criação está o problema de "juntar pessoas que estão trabalhando com o assunto, mas enfocando-os através de temas específicos e diferentes". Clarice Nunes (1991) especifica que a identidade desse GT "passa, de um lado, pela discussão que trava no campo da teoria e da empiria e, de outro, pela pesquisa de fontes para a história da educação brasileira, [...] as quais contribuem decisivamente para construir e redefinir o próprio campo" (BOLETIM ANPED, n. 1-2, jan./ dez. 1991, p. 13).

Contudo, não se pode aqui deixar de mencionar o estudo sobre o GT em análise realizado pela autora Ester Buffa (2016), o qual consiste na sistematização e problematização da produção acadêmica apresentada pelos integrantes do GT História da Educação da ANPED, de 1984 a 2013, com o intuito de constatar sua contribuição para o campo durante estes 30 anos. Nele, Buffa destaca que as questões teórico-metodológicas da História da Educação não podem ser reduzidas meramente ao problema das fontes de investigação, devendo atentar-se também para os processos histórico-societários.

Por meio de um breve histórico, Buffa perpassa desde a criação do GT História da Educação em 1984 e a atribuição de sua função em 1985, assumindo-se como local de 
troca de experiências e discussões das produções científicas de seus participantes. Discorre também acerca da crescente hegemonia da História Cultural no grupo, e em particular da participação do GT em momentos específicos, como a primeira publicação em 1989, a participação na criação da Sociedade Brasileira de História da Educação em 1999, até sua consolidação, ao se tornar parte da constituição da História da Educação no Brasil.

Posteriormente, a autora discorre sobre os estudos já realizados no tocante à atuação do GT 02, por meio da realização de balanço dos estudos apresentados e discutidos no GT a partir da utilização de três artigos científicos, os quais ressaltam o GT como um lugar de produção da pesquisa histórico-educacional brasileira, espaço de debate teórico-metodológico e de surgimento e fortalecimento de novas perspectivas de investigação. Um dos artigos é de Catani e Faria Filho (2002), e identifica três fases do referido GT: a primeira, durante os anos 80, de diversificação epistemológica e temática; a segunda, em 1990, constituindo novos objetos, com as lutas da história da educação dentro da história (processo/disciplina), com a utilização de referenciais teóricos como Bourdieu, Chartier, Foucault, Le Goff, Certeau e Marx; a terceira, até o ano de 2000, com a explosão dos temas e objetos de pesquisa relacionados à História da Educação (Nova História e História Cultural), com novos aportes teórico-metodológicos. Buffa ainda identifica que, na produção do GT de 2005 a 2013, em relação aos temas a maioria absoluta se refere à educação escolar, na primeira metade do século XX, dentro da órbita da denominada Nova História, principalmente a francesa.

A partir desse delineamento histórico do GT 02, percebe-se que este se propõe a problematizar e discutir como as pesquisas da área estão sendo traçadas em âmbito nacional, no intuito de que a História da Educação se firme cada vez mais como um campo científico educacional e historiográfico pertinente frente ao entendimento das diferentes temáticas e problemas que a educação enfrentou e ainda enfrenta no Brasil.
Ressalta-se que a pesquisa ora realizada se propõe a fazer um complemento desse estudo de Ester Buffa, ao analisar os trabalhos do GT de 2015 e 2017, no afã de contribuir para a compreensão da produção sistematizada da História da Educação no Brasil.

\section{Análise dos trabalhos do GT 02 - História da EduCaÇão nas Reuniões NACIONAIS 37 ${ }^{\mathrm{a}}$ E $38^{\mathrm{a}}$. DA ANPED}

A análise revelou no total 28 trabalhos e é composta pela verificação do objeto de pesquisa, tema, tipo de pesquisa, campos temáticos investigativos historiográficos, referenciais teóricos e instituições a que pertencem os autores. Para tanto, foi feita a leitura dos resumos e dos trabalhos na íntegra.

A $37^{\mathrm{a}}$. Reunião Anual da Associação Nacional de Pós-Graduação e Pesquisa em Educação foi efetuada no Campus Florianópolis/ UFSC, no período de 4 a 8 de outubro de 2015 . Essa realização respeitou a decisão em assembleia de 2010, de garantir o caráter itinerante às Reuniões Nacionais da Associação, tendo o objetivo de contribuir para o fortalecimento da Pós-Graduação em todas as regiões do país.

No GT 02 desse ano, foram apresentados 18 trabalhos dos quais se passa a realizar um balanço, visando compreender a produção sistematizada da área. Os objetos de pesquisas se mostraram diversos entre si e as temáticas em alguns casos se repetem, a saber: histórias de vida de determinados autores, análise de livros didáticos, importância da História da Educação nos cursos de Pós-Graduação e na Pedagogia, estudos a respeito de determinados municípios e Estados brasileiros e também sobre histórico de leis.

Em relação ao tipo de pesquisa foram encontradas quatro, sendo que alguns trabaIhos apresentam mais de um tipo. Dentro das pesquisas historiográficas, identificaram-se 17 de história cultural, dois de história política e um de história social, além de uma análise bibliométrica, sendo esta de estado da arte. No tocante aos campos temáticos investigativos, segue quantas vezes cada um foi utilizado, 
contudo, alguns se encaixam em mais de um trabalho: 5 - história da educação nos Estados brasileiros, 4 - história da educação no Brasil, 3 - história da educação nos municípios brasileiros, 2 - história da educação em outros países, 2 - história dos livros didáticos e manuais escolares, 1 - história de impressos, 1 - história dos intelectuais, 1 - história da leitura e escrita, 1 - história das práticas pedagógicas, 1 - história das ideias pedagógicas, 2 - história das instituições escolares.

Quanto ao referencial teórico, apresenta-se os que foram citados mais de uma vez: 5-Roger Chartier, 3 - Marta Maria Chagas de Carvalho, 3- Michel de Certeau, 3 - Diana Gonçalves Vidal, 3 - Jacques Le Goff; 3 - Cynthia Greive Veiga, 2 - Pierre Bourdieu, 2 - António Nóvoa, 2 - José Gonçalves Gondra. Na categoria instituições, nove são públicas e quatro privadas. Identificam-se dentro dessa categoria nas universidades públicas a UFMT, UFPR, UFMG, USP, UFU, UFPel, UFRGS, UNESPAR, UFOP. Entre as universidades privadas, todas são confessionais, são elas: PUC-RJ, PUC-SP, UNISANTOS, UNISINOS.

A $38^{\mathrm{a}}$. Reunião Nacional da ANPED ocorreu na Universidade Federal do Maranhão, nos dias 1 a 5 de outubro de 2017. Nesse encontro foram apresentados 10 trabalhos no GT 02, sendo que seus objetos de estudo são distintos e suas temáticas permeiam em alguns casos coincidências. Foram identificadas as seguintes: instituições de ensino e de pesquisa, estudos sobre determinados municípios e Estados, teóricos e educação em outros países.

Em relação aos tipos de pesquisa, todas são historiográficas, havendo em cada trabaIho, em alguns casos, a identificação de mais de um tipo: 8 - história cultural, 2 - história das ideias, 1 - história política, 1 - história comparada, 1 - história social. Quanto aos campos temáticos investigativos, segue quantas vezes cada um foi utilizado: 3 - história da educação nos Estados brasileiros, 3 - história dos intelectuais, 1 - história dos livros didáticos e manuais escolares, 1 - história da educação nos municípios brasileiros. O referencial teó- rico revelou dois autores que foram citados mais de uma vez: 3 - Luciano Mendes de Faria Filho, 2 - Diana Gonçalves Vidal. No tocante às instituições a que pertenciam os autores, todas são universidades públicas, a saber: UFS, UFVJM, USP, UFMS, UNIFAL, UFRGS, UFG, UFMG, UFPE.

A partir desses dados apresentar-se-á uma análise geral desses trabalhos, no sentido de identificar se há aspectos de conformidade ou discrepâncias em relação às análises já citadas feitas por Ester Buffa.

O número de trabalhos por encontro mostrou-se tão díspar, 18 em 2015 e 10 em 2017, que para ter uma visão mais ampla julgou-se necessário identificar a quantidade de trabalhos dos encontros $33^{\circ}$. a $38^{\circ}$., o que revelou que nesse GT houve um padrão crescente até 2015. Entende-se que para compreender o porquê isso ocorreu seria necessário um estudo que investigasse se isso advém de uma crise do próprio campo, ou se fatores externos como a distância do local do evento de 2017 dos grandes centros do país, junto a problemas econômicos que o Brasil enfrentou nesse ano influenciaram no menor número de trabalhos apresentados.

Constatou-se que os títulos dos trabaIhos e objetos específicos de pesquisa são distintos entre si, sendo que o que coincide são as temáticas e tipo de pesquisa. Observou-se que há temáticas que se sobressaem, como a pesquisa a respeito de instituições de ensino, estudos sobre teóricos da educação e investigações de como a educação se desenvolveu em determinados municípios ou Estados, principalmente no período do início da República brasileira.

No que diz respeito aos tipos de pesquisa desenvolvidos nos trabalhos apresentados, no recorte temporal aqui estudado, houve certa dificuldade em classificar parte dos trabalhos, pois muitos podem ser enquadrados em mais de um tipo. Além disso, a massiva parte dos trabalhos não define em seu corpo ou resumo o tipo de pesquisa que está sendo desenvolvida. Essa dificuldade também foi sentida por José Gonçalves Gon- 
dra, o qual, em sua fala no IX CBHE, ${ }^{1}$ explicitou que ao analisar os tipos de pesquisas desse congresso específico da área da História de Educação no Brasil, sentiu que esse era um exercício complexo, pois percebeu que os trabalhos se encaixavam em mais de uma tipologia de pesquisa.

Nos trabalhos aqui analisados verificou-se que há dois tipos de pesquisa: Análise Bibliométrica e Pesquisa Historiográfica. Nota-se que nos dois encontros nacionais da ANPED, que compõem o recorte temporal desta pesquisa, há predominância das pes- quisas historiográficas, a ponto de serem unânimes no último encontro estudado. Considera-se que há a possibilidade desse fato ter ocorrido por causa do recrudescimento nas últimas duas décadas do desenvolvimento do campo no país, pois conforme demonstram os dados, houve um aumento do número de teóricos e temas nacionais nas pesquisas apresentadas.

Com o intuito de tornar a visualização dos dados mais tangível e possibilitar uma melhor compreensão deste que é um dos principais cernes no desenvolvimento de uma pesquisa científica, foi elaborado o Quadro 1.

Quadro 1 - Tipos de pesquisas e quantidade dessas nos trabalhos apresentados no GT 02 de História da Educação nas reuniões nacionais $37^{\mathrm{a}}$. e $38^{\mathrm{a}}$. da ANPED.

\begin{tabular}{lll}
\hline Reunião Nacional da ANPED & Análise Bibliométrica & Pesquisa Historiográfica \\
\hline \multirow{3}{*}{$37^{\mathrm{a}} \cdot$} & História Cultural -17 \\
& estado da arte -1 & História Política -2 \\
& História Social -1 \\
\hline $38^{\text {a }}$. & História Cultural -8 \\
& 0 & História das Ideias -2 \\
& História Política -1 \\
& História Comparada -1 \\
\hline
\end{tabular}

Fonte: O quadro foi elaborado pelas autoras, a partir de dados disponíveis em http://www. anped.org.br/reunioes-cientificas/nacional. Acesso em 20 nov. de 2017.

Quanto à análise bibliométrica, esta foi utilizada em um dos 28 trabalhos na elaboração de um estudo de estado da arte, que busca identificar por meio de artigos teses e dissertações como se dá a produção acadêmica em Ensino de História da Educação no Brasil (1996-2013). Entende-se que a análise bibliométrica, apesar de não ser uma pesquisa historiográfica, traz bases para esta, ao catalogar e quantificar fontes dentro de um recorte temporal específico, que posteriormente possam ser analisadas e utilizadas em pesquisas. A análise bibliométrica é um recurso metodológico que se destina ao levantamento de um campo científico, na análise e

IX Congresso Brasileiro de História da Educação - 15 a 18 de agosto de 2017, João Pessoa-PB. quantificação dos processos de comunicação escrita existentes em publicações, ressaltando os autores mais citados, os temas em alta e os periódicos mais importantes (PEREIRA; FERRERIA JUNIOR; HAYASHI, 2016).

Em relação às pesquisas do tipo historiográfica, conforme se pode observar no Quadro 1, cinco campos historiográficos foram utilizados nos trabalhos analisados: História Cultural, História Comparada, História Política, História das Ideias e História Social. Em alguns casos, identificou-se que mais de um são utilizados no mesmo trabalho.

Como apontado na introdução, a História da Educação é um campo temático investigativo complexo, que se relaciona com diferentes ciências e campos investigativos. Quanto à História Comparada, que foi utiliza- 
da em um dos trabalhos, essa é uma metodologia histórica ainda em desenvolvimento, e tem se mostrado essencial na renovação das pesquisas históricas, ela deriva dos estudos comparativos que surgiram com a sociologia. Campos (2011) defende que "o método comparativo seria um instrumento que nos possibilita enriquecer as nossas pesquisas, por ampliar o nosso conhecimento" (p. 187). O trabalho que se utilizou desse tipo de pesquisa fez uma comparação entre diferentes aspectos educacionais do Brasil e outro país, no caso a Argentina.

No tocante às histórias Política, das Ideias, Social e Cultural, estas sofreram uma renovação epistemológica conhecida como Nova História, com a eclosão do movimento dos Annales nos anos 1930, que ocorreu principalmente na França e Alemanha, o qual propunha uma nova abordagem metodológica para a história própria para as ciências sociais (MESQUITA, 2011). Dentro dessa perspectiva, a História Política que foi trabalhada há muitos séculos pela perspectiva macro dos centros de poder, no decorrer do século $\mathrm{XX}$, sofreu uma renovação dos paradigmas, questões conceituais e procedimentos metodológicos, ao mudar o enfoque para os micropoderes, fazendo uso do discurso e do imaginário social (BARROS, 2008). A História Política foi empregada em três trabalhos, os quais abordam como decisões políticas em diferentes âmbitos influenciam a educação e o campo científico.

A transição na História das Ideias se dá na mudança de seu foco de interesse na observação do aspecto intrínseco às ideias filosóficas produzidas por sujeitos pensantes pertencentes à elite intelectual, para assumir o objetivo de demonstrar a real dependência desses e dos resultados de suas ilações a uma dimensão da existência coletiva no tempo e no espaço (MESQUITA, 2011). A História das Ideias serviu como base para dois dos traba-
Ihos historiográficos aqui analisados, ao investigarem como propostas ideológicas de diferentes teóricos foram utilizadas por educadores ou políticos na educação.

Enquanto que, a História Social começou a ser trabalhada mais marcadamente sob novas perspectivas, a partir dos anos 1960 , ao ampliar e legitimar novas áreas para investigação como o urbano, a mulher, a família, a educação e outros. Metodologicamente, houve acentuação do caráter descritivo, maior explicitação teórica e localização mais precisa dos objetos (FENELON, 1993). No total de trabalhos historiográficos examinados neste estudo a História Social foi utilizada em dois deles, ao apreciar regras, normas e costumes sociais que geram padrões de comportamento atrelados à educação não formal.

A História Cultural, por sua vez, segundo Peter Burke (2008), é renovada nos anos 1970 e passa a trazer uma gama tão grande de campos temáticos investigativos em seu interior que gera sucessivos problemas, como também passa a se relacionar com "o que os historiadores fazem ao tempo em que vivem" (p. 7). Tem-se um movimento que vai da perspectiva das histórias nacionais, para um interesse cada vez maior nos valores defendidos por grupos particulares em locais e períodos específicos, a partir de uma preocupação com o simbólico e suas interpretações.

Dentro da miríade de campos temáticos investigativos que a História Cultural abarca, foi possível identificar que ela aparece em 25 trabalhos, nos quais foram identificados 11 tipos: história dos intelectuais, história das instituições escolares, história da leitura e escrita, história da educação no Brasil, história da educação nos Estados brasileiros, história de impressos, história das ideias pedagógicas, história da educação de outros países, história das práticas pedagógicas, história da educação nos municípios brasileiros, história dos livros didáticos e manuais escolares. 
Quadro 2 - Campos temáticos investigativos da História Cultural identificados nos trabalhos apresentados no GT 02 - História da Educação, nas reuniões nacionais $37^{\mathrm{a}}$. e $38^{\mathrm{a}}$. da ANPED.

\begin{tabular}{lc}
\hline Campos temáticos investigativos da História Cultural & $\begin{array}{l}\text { Quantidade em que } \\
\text { foram utilizados }\end{array}$ \\
\hline História da educação nos Estados brasileiros & 8 \\
\hline História dos intelectuais & 4 \\
\hline História da educação no Brasil & 4 \\
\hline História da educação nos municípios brasileiros & 4 \\
\hline História dos livros didáticos e manuais escolares & 3 \\
\hline História das instituições escolares & 3 \\
\hline História da educação de outros países & 2 \\
\hline História das ideias pedagógicas & 1 \\
\hline História de impressos & 1 \\
\hline História das práticas pedagógicas & 1 \\
\hline História da leitura e escrita & 1 \\
\hline
\end{tabular}

Fonte: $\mathrm{O}$ quadro foi elaborado pelas autoras, a partir de dados disponíveis em http://www.anped.org.br/reunioescientificas/nacional. Acesso em 20 nov. de 2017.

O Quadro 2 permite que se observe o quanto cada um dos campos temáticos investigativos foi empregado nos 25 trabalhos que utilizaram a História Cultural. Pesquisas que abordam a história da educação em Estados brasileiros se destacam, sendo utilizada em oito dos trabalhos, o predomínio está no estudo do período do início da República no Brasil quando os Estados passam a ficar responsáveis pelo ensino primário. Percebe-se que as pesquisas se concentram em Estados situados no centro oeste, sudeste e sul do país. Foram identificados como objeto de estudo Goiás, Mato Grosso, Mato Grosso do Sul, Minas Gerais, Paraná e São Paulo.

A História dos Intelectuais aparece em quatro trabalhos, em pesquisas que promovem o estudo de teóricos e intelectuais, tanto nacionais, quanto estrangeiros, envolvidos diretamente com o campo educacional. Com o mesmo número de trabalhos está a História da educação no Brasil, em pesquisas que per- passam temáticas relativas à produção acadêmica da história da educação no país, difusão de sistemas de ensino e políticas públicas.

O campo temático investigativo história da educação nos municípios brasileiros também vigora em quatro trabalhos, com pesquisas que estudam políticas públicas locais. Três dos municípios estudados ficam no Estado de Minas Gerais, sendo eles Mariana, Portelinha e Diamantina, e um em Mato Grosso do Sul, Campo Grande.

A história dos livros didáticos e manuais escolares está contemplada em três trabaIhos: uma pesquisa estuda manuais de ensino mútuo no Brasil e Argentina, a segunda faz uma análise de um livro didático utilizado no Rio Grande do Sul, e a última faz um estudo dos livros didáticos empregados nas Escolas Normais no Paraná. Quanto à história da educação de outros países, há uma pesquisa sobre a Argentina e outra sobre Cuba. Na história das instituições escolares, dois objetos de 
estudo estão no Estado de Minas Gerais, uma escola secundária e um Grupo Escolar, e um Instituto de Nova Friburgo no Rio de Janeiro.

A história das ideias pedagógicas abarca um trabalho sobre o movimento da Escola Nova. Em relação à história de impressos, há uma pesquisa acerca de como uma revista de cunho religioso era utilizada em escolas. No tocante à história das práticas pedagógicas, observou-se um trabalho relativo à prática de professores primários na província do Paraná. E a respeito da história da leitura e escrita, identificou-se um trabalho sobre projetos de leitura pública dedicados às crianças.

Nota-se, então, que nesse grupo específico de pesquisadores de história da educação há predominância de pesquisas relativas aos Estados brasileiros, principalmente os que se encontram nas áreas com maior concentração de programas de pós-graduação. Na mesma linha, também se destacam as pesquisas sobre história da educação no Brasil e em municípios, assim como, de intelectuais ligados à educação.

A análise dos referenciais teóricos utilizados nesses dois encontros nacionais da ANPED destaca os autores que foram citados acima de uma vez no total de pesquisas. Salienta-se que os teóricos apontados têm direta relação com os tipos de pesquisas apresentados anteriormente, pois de acordo com estas há um referencial teórico próprio que as embasa. Nota-se, que na busca do referencial teórico, poucos resumos dos trabalhos permitiram identificá-los, portanto fez-se a leitura dos trabalhos na íntegra.

No total, foram identificados dez teóricos apontados como referencial de 28 trabaIhos historiográficos analisados nesse quesito, constam cinco teóricos brasileiros e cinco de outros países. Quanto aos autores brasileiros, segue quantas vezes cada um foi citado como referencial: 5 - Diana Gonçalves Vidal, 3 - Luciano Mendes de Faria Filho, 3 - Marta Maria Chagas de Carvalho, 3 - Cynthia Greive Veiga, 2 - José Gonçalves Gondra. Considera-se que isso possa ser interpretado como um movimento de intensificação dentro dos estu- dos de História da Educação no Brasil, nesse início da segunda década do século XXI, onde questões específicas de cunho nacional e pesquisadores brasileiros têm se destacado e dedicado na produção de estudos e materiais como pesquisas, livros e artigos, que têm servido de base para a nova geração de pesquisadores desenvolverem suas próprias investigações.

Em relação aos autores estrangeiros, nota-se a preponderância dos franceses, que segundo Peter Burke (2008), são os principais teóricos que se debruçam sobre as questões da História Cultural. Apresentam-se de acordo com o número de vezes que foram citados como referencial: 5 - Roger Chartier, 3 - Michel de Certeau, 3 - Jacques Le Goff, 2 - Pierre Bourdieu. Outro autor estrangeiro indicado duas vezes como referencial é o português António Nóvoa.

No sentido de traçar uma perspectiva das instituições a que pertencem os autores responsáveis pelas pesquisas aqui analisadas e no intuito de delinear um perfil desse grupo de pesquisadores da história da educação no Brasil identificaram-se no total 19 universidades. Nesse quesito, observou-se a prevalência de universidades públicas federais: Universidade Federal do Mato Grosso - UFMT, Universidade Federal do Paraná - UFPR, Universidade Federal de Minas Gerais - UFMG, Universidade Federal de Uberlândia - UFU, Universidade Federal de Pelotas - UFPel, Universidade Federal do Rio Grande do Sul UFRGS, Universidade Federal de Ouro Preto UFOP, Universidade Federal de Sergipe - UFS, Universidade Federal dos Vales do Jequitinhonha e Mucuri - UFVJM, Universidade Federal do Mato Grosso do Sul - UFMS, Universidade Federal de Alfenas - UNIFAL, Universidade Federal de Goiás - UFG, Universidade Federal de Pernambuco - UFPE. Considerando-se atentamente essa lista, composta por 13 instituições, percebe-se a concentração de cinco delas no Estado de Minas Gerais.

No que diz respeito às universidades públicas estaduais, identificaram-se a Universidade de São Paulo - USP e a Universidade 
Estadual do Paraná - UNESPAR. E quanto às universidades privadas, todas são confessionais. São elas: Pontifícia Universidade Católica do Rio de Janeiro - PUC-RJ, Pontifícia Universidade Católica de São Paulo - PUC-SP, Universidade Católica de Santos - UNISANTOS, Universidade do Vale do Rio dos Sinos - UNISINOS. No total, percebe-se que, além da predominância de instituições federais já indicadas, também é possível identificar a concentração de universidades do sudeste e sul do Brasil.

\section{CONSIDERaÇões FINAIS}

Esta pesquisa revelou que há uma miríade de questões e temas sendo trabalhados no campo da História da Educação no Brasil, no grupo específico que participa dos eventos da ANPED, fato que faz ponderar acerca dos elementos que envolvem os aspectos teórico-metodológicos inerentes à História da Educação, por exemplo, a relação que esta mantém com a História em si ou quais são seus aportes teóricos. Procurou-se assim, trazer à tona alguns elementos que compõem as discussões desse campo de estudo.

Quanto à relação da História da Educação, com a historiografia contemporânea, Fonseca (2003) define que ambas se apoiam na História Nova surgida da geração dos Annales a partir de 1929, a qual abarca diferentes dimensões da vida, com novos objetos, fontes e metodologias, que trouxeram recortes mais particularizados e temas específicos. Contudo, a autora realça que ainda não está completamente delineada a questão de onde se encaixa a História da Educação, posto que surgiu como uma disciplina e há discussões se seria uma área, um campo, ou uma vertente da História e, além disso, percebe-se que seus estudos têm dialogado cada vez mais com a História Cultural, História Social e História das Mentalidades.

$O$ consenso acadêmico, nesta segunda década do século XXI, é que a História da Educação não é um campo autônomo com metodologias próprias, mas tem suas espe- cificidades na utilização de metodologias e procedimentos, por exemplo, da História Cultural. Assim, a História da Educação é considerada um campo temático ou de pesquisa, com objetos próprios.

Nesse contexto, a pesquisa realizada identificou os temas, teóricos e principais correntes historiográficas que vêm sendo discutidos em um grupo específico no campo da História da Educação, além das instituições a que os pesquisadores pertencem, por meio da análise dos últimos dois encontros nacionais da ANPED - Associação Nacional de Pós-Graduação e Pesquisa em Educação, que abarcam os anos de 2015 e 2017.

Os principais pontos que se ressaltaram na análise revelam que há congruências com os delineamentos anteriores feitos sobre o GT 02 de História da Educação da ANPED, que identificaram a educação escolar como principal foco de pesquisa. Constatou-se que, ainda que os objetos de pesquisa sejam díspares, as temáticas, em muitos casos, mostram-se confluentes, sendo que os que mais se ressaltaram foram pesquisas sobre instituições de ensino e estudos sobre teóricos da educação. Contudo, um dos eixos que mais se destacaram e não foi citado nos levantamentos anteriores do GT foram as investigações de como a educação se desenvolveu em determinados municípios ou Estados, principalmente no período do início da República brasileira.

Quanto ao tipo de pesquisa, observou-se que como no estudo de Ester Buffa há uma hegemonia do uso da Nova História, principalmente da História Cultural, mas também foram verificadas pesquisas no âmbito das histórias Política, das Ideias e Social. A análise dos principais teóricos corrobora esses achados ao identificar autores estrangeiros, especialmente os franceses, que se debruçam nas questões da História Cultural. Mas, esta análise também revelou que metade dos autores é brasileira, o que se entende como sendo um indício de considerável aporte de pesquisas próprias no país.

Um ponto não analisado nos estudos anteriores é a qual instituição pertencem os 
pesquisadores que participaram dos dois encontros aqui analisados. Percebeu-se que há uma correlação direta entre o objeto das pesquisas e a localização das instituições, ou seja, os Estados ou regiões do país que mais têm participado geram uma concentração de pesquisa dentro de seus perímetros, o que causa um vácuo de pesquisa sobre as outras regiões do país. As universidades federais se sobressaem, com destaque para as localizadas no Estado de Minas Gerais. Nota-se uma predominância do Sudeste e Sul do país, de acordo com a Plataforma Sucupira a quantidade do total de cursos de Pós-Graduação dessas duas regiões é extremamente discrepante frente às outras regiões do Brasil, principalmente no
Sudeste. Assim, considera-se pertinente a atitude da ANPED em não promover mais suas reuniões apenas no Sudeste, para propiciar que pesquisadores e estudantes de outras regiões tenham a possibilidade de participar das reuniões nacionais e expor seus estudos para a comunidade acadêmica.

Dessa forma, essa complementação do delineamento do GT 02 de História da Educação da ANPED pretendeu contribuir para uma melhor problematização e discussão de como as pesquisas da área estão sendo desenvolvidas em âmbito nacional, no intuito de compreender como a História da Educação está se firmando cada vez mais como um campo científico educacional e historiográfico no Brasil.

\section{REFERÊNCIAS}

ANPED. Associação Nacional de Pós-Graduação e Pesquisa em Educação. Disponível em: $<$ http://www.anped.org.br/>. Acesso em: 6 mai. 2017.

ANPED. GT02 - História da Educação. Disponível em: http://www.anped.org.br/grupos-de-trabalho/gto2---história-da-educação. Acesso em: 6 mai. 2017.

ANPED. Reuniões Nacionais. Disponível em: http://www.anped.org.br/reunioes-cientificas/nacional. Acesso em: 20 mai. 2017.

ANPED. Sobre a Anped. Disponível em: http://www.anped.org.br/sobre-anped. Acesso em 6 mai. 2017.

BARROS, José D’Assunção. História Política - Dos objetos tradicionais ao estudo dos micropoderes, do discurso e do imaginário. Escritas: Revista do Curso de História de Araguaína, [S.I.], v. 1, abr. 2015. Disponível em: https://sistemas.uft.edu.br/periodicos/index.php/escritas/article/ view/1278. Acesso em: 6 mai. 2017.

BORGES, Bruno Gonçalves; GATTI Décio Júnior. O Ensino de História da Educação na Formação de Professores no Brasil Atual. Revista HISTEDBR On-line, Campinas, n. 40, p. 24-48, dez. 2010. Disponível em: file:///C:/Users/carom/Downloads/8639804-10362-1-PB.pdf. Acesso em: 20 mai. 2017.

BUFFA, Ester. Os 30 anos do GT História da Educação: sua contribuição para a constituição do campo. Revista Brasileira de História da Educação, Maringá-PR, v. 16, n. 4 (43), p. 393-419, out./ dez. 2016. Disponível em: http://www.rbhe.sbhe.org.br/index.php/rbhe/article/view/885/pdf 162. Acesso em: 6 mai. 2017.

BURKE, Peter. O que é História Cultural?. Rio de Janeiro: Zahar, 2008, 215 p.

CAMPOS, Carlos Eduardo da Costa. A História Comparada e suas Vertentes: uma revisão historiográfica. Historiæ, Rio Grande, 2 (3): p. 187-195, 2011. Disponível em: file:///C:/Users/carom/ Downloads/2618-7228-1-PB.pdf. Acesso em 6 mai. 2017. 
CATANI, Denice Bárbara; FARIA FILHO, Luciano Mendes de. Um lugar de produção e a produção de um lugar: a história e a historiografia divulgadas pelo GT História da Educação da ANPEd (1985-2000). Revista Brasileira de Educação (19), p. 113-128, jan./abr. 2002. Disponível em: http:// www.scielo.br/pdf/rbedu/n19/n19a09.pdf. Acesso em: 6 mai. 2017.

FARIA FILHO, Luciano Mendes de; RODRIGUES, José Roberto Gomes. A história da educação programada. Uma aproximação da História da Educação ensinada nos cursos de Pedagogia em Belo Horizonte. Revista Brasileira de História da Educação, n. 6. jul./dez. p. 159-175, 2003. Disponível em: http://www.rbhe.sbhe.org.br/index.php/rbhe/article/viewFile/221/230. Acesso em: 6 mai. 2017.

FENELON, Déa Ribeiro. Cultura e História Social: historiografia e pesquisa. Projeto História. São Paulo, n. 10, p. 73-90, dez. 1993. Disponível em: file:///C:/Users/carom/Downloads/12105-29012-1SM.PDF. Acesso em: 6 mai. 2017.

FONSECA, Thaís Nivea de Lima e. História da Educação e História Cultural. In: FONSECA, Thaís Nivea de Lima e; VEIGA, Cynthia Greive (Orgs.). História e Historiografia da Educação no Brasil. Belo Horizonte: Autêntica, 2003, 288 p.

MESQUITA, Gustavo Rodrigues. Da história das ideias à história social das ideias: entre a renovação epistemológica e a prática historiográfica. Em Tempo de Histórias - Publicação do Programa de Pós-Graduação em História da Universidade de Brasília PPG-HIS, nº 18, Brasília, p. 01-27, jan./jul. 2011. Disponível em: file:///C:/Users/carom/Downloads/4295-13520-1-PB.pdf. Acesso em: 30 mai. 2017.

NUNES, Clarice. 14 ${ }^{\mathrm{a}}$. Reunião Anual da Anped. Boletim Anped, n. 1-2, p. 10-13, jan./dez. 1991. Disponível em: http://www.anped.org.br/grupos-de-trabalho/gt02-\%E2\%80\%93-hist\%C3\%B3ria-da-educa\%C3\%A7\%C3\%A30. Acesso em: 30 mai. 2017.

NUNES, Clarice. Ensino e historiografia da educação. Problematização de uma hipótese. Revista Brasileira de Educação. Rio de Janeiro, n. 1, p. 67-79, jan./fev./mar./abr. 1996. Disponível em: http://anped.tempsite.ws/novo_portal/rbe/rbedigital/RBDE01/RBDE01_07_CLARICE_NUNES. pdf. Acesso em: 6 mai. 2017.

PEREIRA, Maria Aparecida; FERREIRA JR., Amarílio; HAYASHI, Maria Cristina Piumbato Innocentini. História da Educação nas páginas da revista do Instituto Histórico e Geográfico de São Paulo. Revista Brasileira de História da Educação, Maringá-PR, v. 16, n. 3 (42), p. 59-90, jul./set. 2016. Disponível em: file:///C:/Users/carom/Downloads/686-3162-2-PB\%20(1).pdf. Acesso em 20 mai. 2017.

PLATAFORMA SUCUPIRA. Cursos Recomendados e Reconhecidos - Região. Disponível em: https://sucupira.capes.gov.br/sucupira/public/consultas/coleta/programa/quantitativos/quantitativoRegiao.jsf;jsessionid=IpC19tcuSCVdbQWNHKsjYjWE.sucupira-213. Acesso em: $1^{\circ}$. jun. 2017.

SAVIANI, Dermeval. Aberturas para a História da Educação: do debate teórico-metodológico no campo da história ao debate sobre a construção do sistema nacional de educação no Brasil. Campinas: Autores Associados, 2013, 277 p. 


\section{SOBRE AS AUTORAS}

\section{CAROLINA MARTIN}

Doutoranda em Educação na UNIMEP - Universidade Metodista de Piracicaba (início 2016). Mestrado em Educação pela UNIMEP (2014). Graduação em Pedagogia pela UNISANTOS (2009) e Arquitetura e Urbanismo pela Mackenzie (1999).

caromartin@uol.com.br

\section{MilenA Pfister}

Atualmente, é professora do Centro Universitário Salesiano de São Paulo - Unidade de Americana e Doutoranda em Educação pela Universidade Metodista de Piracicaba (início 2016). Graduação em Direito pela Universidade Metodista de Piracicaba (2000) e mestrado em Direito pela Universidade Metodista de Piracicaba (2005).

milenapfister@hotmail.com

\section{RENATA RÉ BOLLIS}

Doutoranda em Educação pela Universidade Metodista de Piracicaba - UNIMEP (início 2016). Mestre em Educação pela Universidade Metodista de Piracicaba (2015). Graduação em Bacharelado em Ciências Jurídicas e Sociais pela Universidade Metodista de Piracicaba - UNIMEP (2003). Graduanda em Pedagogia pela UNICID (início 2017).

renata.bollis@hotmail.com

Recebido em: 29/03/2018

Aprovado em: 21/06/2018 